\title{
MANAGEMENT PROCESSES RECONSTRUCTION OF HISTORICAL BUILDINGS SUPPORTED BY SMART TECHNOLOGY—A CASE STUDY OF FUZHOU CITY
}

\author{
W. QU ${ }^{1}$, M. J. $\mathrm{LI}^{1}$, X. Q. ZHANG ${ }^{1}$, Z. WANG ${ }^{1}$ \\ ${ }^{1}$ Beijing Tsinghua Tongheng Urban Planning and Design Institute, China \\ (quwei, limingjie, zhangxiaoqing, wangzhe)@thupdi.com
}

Commission II, WG II/8

KEY WORDS: Intelligent management, Process reengineering, System of information, Historical buildings, New technology, Fuzhou

\begin{abstract}
:
This research is based on the projects that Fuzhou has carried out and in developing, regarding to historical building survey, registration, documentation, publication, construction, and daily management business. It integrates smart technologies such as geographic information technology and visualization technology to develop a historical building conservation management database and Fuzhou historical building conservation planning management system. The construction of Fuzhou historical building conservation planning management system, promoted the reconstruction of historical building management processes, achieved efficient and advanced administrative management, achieved scientific and intelligent conservation of historical buildings, and improved the conservation and management of Fuzhou historical buildings in the field of technology level.
\end{abstract}

\section{INTRODUCTION}

Fuzhou is located in the eastern part of Fujian Province, the coastal areas of China, and it has a history of more than 2,200 years. It is an important gateway to the ancient 'Silk Road on the Sea', and was approved among the second batch of national historical and cultural cities in 1986.

In December 2017, the Ministry of Housing and Urban-Rural Development of the People's Republic of China decided to list 10 cities including Fuzhou as the first batch of pilot cities for the protection and utilization of historical buildings. From then on, the implementation of the protection and utilization work of historical buildings in Fuzhou officially launched.

\section{DEMAND ANALYSISS}

With the implementation of the pilot work for more than one year, a lot of efforts in protection and utilization of historical buildings had been made in Fuzhou. And during the project work, it was found that there were problems and demands in data management and business management in the protection and utilization of Fuzhou historical buildings.

Data management: At present, the information of historical buildings in Fuzhou was mainly stored in different departments in the form of planning data and research data. The formats of such data were basically paper-based or PDF-format or electronic text or JPG-format drawings. The formats were complex and diverse, without unified data standard, and thus the utilization efficiency of data was very low. Under such situation, it was difficult to apply intelligent data management and analysis.

Business management: The business work relating to Fuzhou historical buildings mainly included the daily inspection and maintenance of historical buildings, as well as the repairing, migration, emergency reinforcement projects, etc. At present, the business management of historical buildings in Fuzhou still used manual filling and submitting of paper-based work orders for business circulation, and the daily management work was inefficient. In addition, since the operator's on-site discovery of problems could not be timely and effectively reported to the higher authorities, and thus the managers in charge couldn't grasp the first-hand data in time, it was easy to cause inadequate supervision.

\section{SOLUTIONS}

Based on the above requirements, we put forward the following solutions:

For data management needs, first of all, a data production tool should be constructed, kinds of historical Buildings data such as planning result data, census statistics data and archive data in PDF or JPG format would be encoded into the database according to Fuzhou historical Buildings data standard system. Then, a set of database system should be constructed to store data standardly and unitedly. The database system would provide data support for the management decision.

For the business management needs, on the one hand, the historical Buildings inspection management function should be built. The field staff reported the problems during the inspection in real time through APP, and the manager supervised the inspection work through the web-side system. On the other hand, the historical Buildings construction review management function should be constructed to realize the digital management of kinds of electronic materials in the construction review process of historical Buildings.

\section{SYSTEM CONSTRUCTION}

By integrating geographic information technology and visual display technology, the intelligent management system of Fuzhou historical buildings had been designed and built, which integrated data management and business management of historical 
buildings. It assisted managers to rebuild the management process of historical buildings, and provided new ideas to pave new ways for the protection and utilization of historical buildings in Fuzhou.

A layered design architecture was adopted for the intelligent management system of Fuzhou historical buildings, which can be divided into data layer, service layer and application layer, as shown in Figure 1.

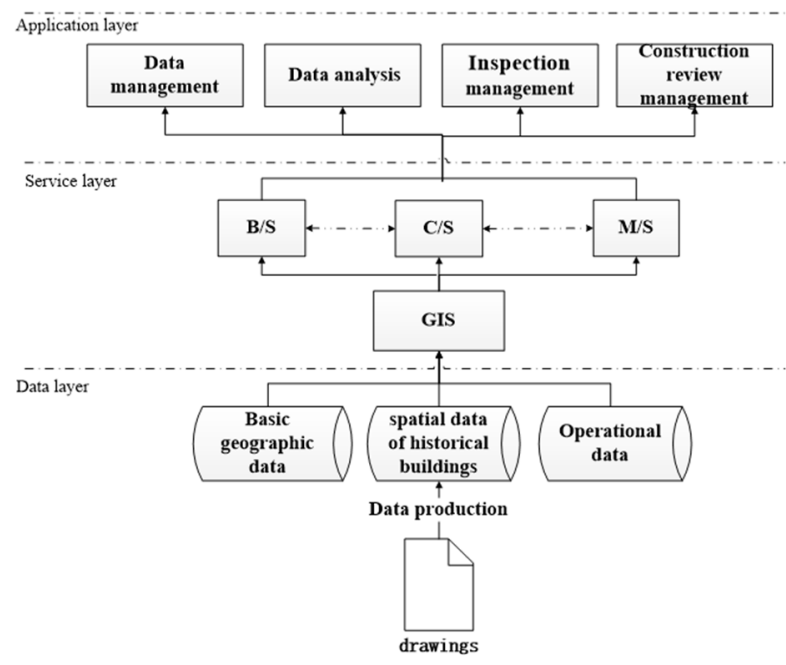

Figure 1. System architecture

The data layer stored and managed basic geographic information data, historical buildings spatial data, and operational data. Centralized storage and management of data resources maximized information sharing, reduced data redundancy and prevented redundant construction.

The service layer was above the data layer and served to provide a common service interface for specific business applications. The system introduced hybrid architecture included $\mathrm{M} / \mathrm{S}$ (Mobile/Server), B/S (Browser/Server), and C/S(Client/Server), to avoid information barriers and work isolation caused by spatial isolation between managers and field operators. And also, to achieve data sharing and synchronization between the two parties. And the application of GIS realized the visualization of historical buildings.

The application layer contained specific applications of historical Buildings management business in Fuzhou, such as data management of historical Buildings, data analysis of historical Buildings, historical Buildings inspection, and construction management, etc. Specific functional modules as followed:

\subsection{Historical buildings map display module}

The module integrates basic topographic data with historical building data to realize historical building archive management and data understanding functions. In addition, the module achieves hierarchical demonstration of historical building attribute information, and supports sift and query spatial information and attribute information by attribute conditions, administrative divisions and custom space ranges. The module is convenient for managers to grasp all the information they need quickly, and provide data support for managers decision-making. The module mainly accomplishes the following functions:
4.1.1 Map Browsing: Zoom in, zoom out, and pan to display Fuzhou historical building map information.

4.1.2 Layer Management: The various map layers presented in a tree-structured list are categorized and displayed by layer classification, the layer can be switched on and off to adjust its visibility.

4.1.3 Historical Building Information Query and Retrieval: The module enables users to retrieve historical building information based on different conditions, the system will return the result of the query according to the query conditions input by the user, and allow users to export the query result in EXCEL format, which is convenient for users to download and manipulate data.

4.1.4 Historical Building Information Viewing: The interactive map allows users to click on the historical building. Also, they are able to click on the historical building in the search result list, the system will present the basic information of the historical building and its related photos if available.

4.1.5 Statistical Analysis: The module provides categorical data of historical building and quantitative statistics, and they are displayed in the form of statistical tables and statistical charts. For instance, the building area and number of buildings can be counted according to districts.

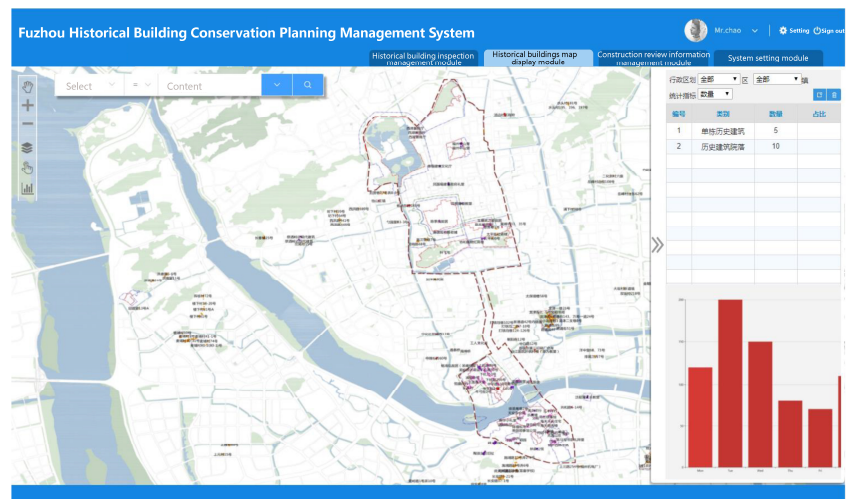

Figure 2. Statistics and analysis of historical buildings

\subsection{Historical building inspection management module}

It realizes the digitalization and whole process supervision of the daily inspection business of Fuzhou's historical buildings, and provides functions such as enables users to upload text and picture format inspection information, to look over inspection information. The module opens to two kinds of users: front-line managers and municipal departments, and assists The Famous City Management Committee to grasp the latest news of historical buildings in time, to manage any behaviors that violate laws and regulations, and endanger the historical buildings immediately. The module mainly accomplishes the following functions: 
4.2.1 Inspection information reporting: Provides information reporting interface selection according to the type of inspection (front-line manager inspection, municipal departments inspection); provides reporting information editing function and supports functions of taking on-site photo or uploading local image (Figure 4).

4.2.2 Inspection information management: According to the selection time, inspection type and other sifting conditions, the query and inspection function of the historical building inspection information can be realized under the selected conditions, and the detailed attribute information of the inspection result can be viewed to understand the specific problem.

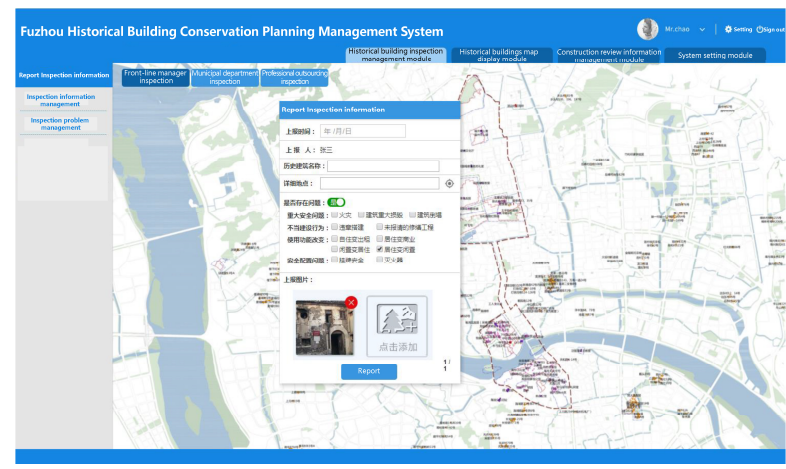

Figure 3. Inspection information reporting

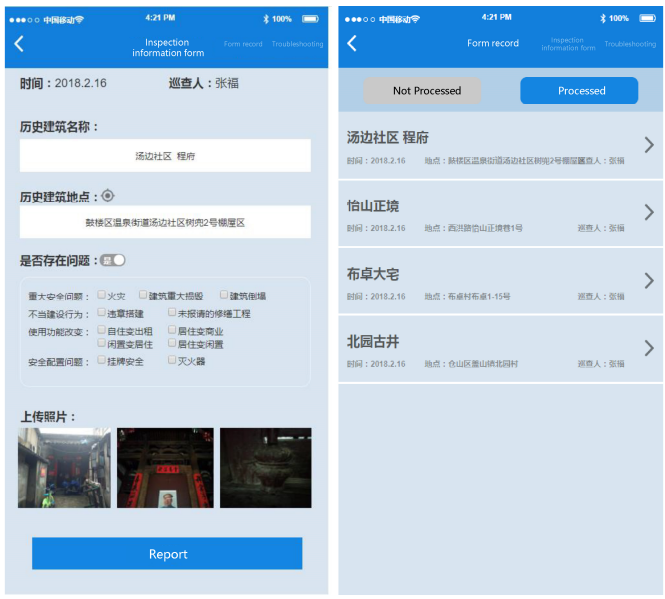

Figure 4. Inspection of historical buildings by APP

\subsection{Construction review information management module}

This module provides the functions of archiving, inquiring and data exporting of various electronic materials during the review of historical building construction process(W. J. Yang, et al. 2018).The module mainly accomplishes the following functions:

4.3.1 Daily management of maintenance information: The module realizes the information management of historical building daily maintenance in maintenance plan design company, the record date of maintenance plan, and plan content. Also, the module supports sifting, retrieval, data import and export based on conditions like historical building name and administrative area.
4.3.2 Management of emergency repair information: To realize the comprehensive information management of historical building emergency repair in urgent repair plan design company, record date of urgent repair plan, and the plan content. Also, the module allows users to search by keywords, and export and import the dataset.

4.3.3 Information management of the original site repair: To realize the comprehensive information management of historical building original site repair work in original site repair design plan company, repair design plan, construction plan content, plan review opinion, and commencement of construction record. Also, the module allows users to search by keywords, and export and import the dataset.

4.3.4 Information management of relocation protection: To realize the comprehensive information management of historical building relocation protection work in relocation plan, review of relocation plan, municipal government's approval of relocation plan, provincial department's approval of relocation plan and project commencement record. Also, the module allows users to search by keywords, and export and import the dataset.

\subsection{System setting module}

This module is able to manage the software's overall environment initial configuration, database maintenance, operation logs, and role permissions uniformly. It includes management of users and user groups, management and maintenance of account information and passwords, configuration management of userrole, role-permissions, setting of system parameters, and backup management of system logs and databases. The module mainly accomplishes the following functions:

4.4.1 User authority management: This module is able to define corresponding operation authority according to different roles of users. System administrators have the authority to manage and maintain the systems and data, and they can authorize different types of users. By managing the operation authority of all user roles, the user is prevented from unauthorized operations or making revision and deletions of data, ensuring the system data is secured and system services are normally distributed and implemented.

4.4.2 Log management: The module provides a complete log and error management mechanism by logging each step of message process, and recording various operations of the system, including management functions such as operation records, access and deletion.

\section{CONCLUSIONS}

This paper deeply analyzed the actual needs of users in the management process of historical buildings in Fuzhou, and built an intelligent management system of historical Buildings. On the one hand, a digital archive of historical Buildings had been provided. It effectively improved the office efficiency, and reduced the cost of data management of historical Buildings. On the other hand, the APP system had been built to achieve the information exchange between managers and field operators, reducing information silos, it also provided platform support for the reconstruction of management process of historical Buildings.

During the project work, it was found that Fuzhou historical buildings have some characteristics, such as large number, 
unclear ownership, absence of legislation, lack of funds, insufficient manpower and imperfect management mechanism, etc. Therefore, it is very difficult for the government departments to manage historical buildings effectively by themselves. How to mobilize the stakeholders of historic buildings and find the best way to protect and utilize historical buildings (X. Chen, 2007). and make the protection and utilization of historical buildings more scientific, technological, transparent and convenient will be an important research content in the next step.

\section{REFERENCE}

W.J.Yang, L.Guo, Z.T.Su, F.Chen, Z.J.Xu, Z.H.Liang, 2018. Research of Historical Building Conversation Based on integrated Smart Management System Case Study on the City of Chaozhou. Geomatics and spatial information technology, 41(2), 21-23.

X.Chen, 2007. Impression of historical building conservation in Europe. Shan Xi architecture, 33(24), 25-26. 